\title{
Germinal center kinase-like kinase (GLK/MAP4K3) expression is increased in adult-onset Still's disease and may act as an activity marker
}

Der-Yuan Chen ${ }^{1,2,3^{*}}$, Huai-Chia Chuang ${ }^{4+}$, Joung-Liang Lan ${ }^{1,2,3+}$, Yi-Ming Chen ${ }^{1,2+}$, Wei-Ting Hung ${ }^{1}$, Kuo-Lung Lai ${ }^{1}$ and Tse-Hua $\operatorname{Tan}^{4,5}$

\begin{abstract}
Background: Germinal center kinase-like kinase (GLK, also termed MAP4K3), a member of the MAP4K family, may regulate gene transcription, apoptosis and immune inflammation in response to extracellular signals. The enhanced expression of GLK has been shown to correspond with disease severity in patients with systemic lupus erythematosus. We investigated the role of GLK in the pathogenesis of adult-onset Still's disease, which shares some similar clinical characteristics with systemic lupus erythematosus.
\end{abstract}

Methods: The frequencies of circulating GLK-expressing T-cells in 24 patients with active adult-onset Still's disease and 12 healthy controls were determined by flow cytometry analysis. The expression levels of GLK proteins and transcripts were evaluated in peripheral blood mononuclear cells by immunoblotting and quantitative PCR. Serum levels of T helper (Th)17-related cytokines, including IL-1 $\beta$, IL-6, IL-17 and TNF- $\alpha$, were measured by ELISA.

Results: Significantly higher median frequencies of circulating GLK-expressing T-cells were observed in patients with adult-onset Still's disease (31.85\%) than in healthy volunteers $(8.93 \%, P<0.001)$. The relative expression levels of GLK proteins and transcripts were also significantly higher in patients with adult-onset Still's disease (median, 1.74 and 2.35 , respectively) compared with those in healthy controls ( 0.66 and 0.92 , respectively, both $P<0.001$ ). The disease activity scores were positively correlated with the frequencies of circulating GLK-expressing T-cells $(r=$ $0.599, P<0.005)$ and the levels of GLK proteins $(r=0.435, P<0.05)$ or GLK transcripts $(r=0.452, P<0.05)$ in patients with adult-onset Still's disease. Among the examined Th17-related cytokines, elevated levels of serum IL-6 and IL-17 were positively correlated with the frequencies of circulating GLK-expressing T-cells and the levels of GLK proteins as well as transcripts in patients with adult-onset Still's disease. GLK expression levels decreased significantly after effective therapy in these patients.

Conclusions: Elevated expression levels of GLK and their positive correlation with disease activity in patients with adult-onset Still's disease indicate that GLK may be involved in the pathogenesis and act as a novel activity biomarker of this disease.

Keywords: Adult-onset Still's disease, GCK-like kinase (GLK, MAP4K3), mitogen-activated protein kinases (MAPKs), pathogenesis, Th17-related cytokines

\footnotetext{
* Correspondence: dychen@vghtc.gov.tw

† Contributed equally

'Division of Allergy, Immunology and Rheumatology, Taichung Veterans General Hospital and Faculty of Medicine, National Yang Ming University,

Taiwan

Full list of author information is available at the end of the article
} 


\section{Background}

Mitogen-activated protein kinases (MAPKs) comprise a family of cytoplasmic serine/threonine protein kinases that are involved in the regulation of key cellular processes including gene induction, cell proliferation, and inflammatory responses $[1,2]$. There are three major families of MAPKs, namely p38 MAPK, extracellularregulated protein kinase and $\mathrm{c}$-Jun $\mathrm{N}$-terminal kinase (JNK) [3]. Wong et al. showed that activation of NF- $\kappa \mathrm{B}$, JNK and p38 MAPK play crucial roles in cytokinemediated signaling pathways in T helper (Th) cells [4]. Moreover, the abnormal activation of intracellular MAPK upon IL-18- stimulation may account for hyperactivity of peripheral lymphocytes in systemic lupus erythematosus (SLE) [5]. A recent study demonstrated that activation of p38 MAPK contributes to Th17-cell effector function as well as the pathogenesis of Th17mediated disease [6].

MAPK activation is mediated by upstream MAPK kinases, termed MAP2Ks (MKKs) and MAP3Ks (MKKKs). MAP4Ks, upstream kinases of MAP3Ks, likely regulate gene transcription, cell growth, apoptosis, and immune inflammation in response to extracellular signals $[7,8]$. Germinal center kinase-like kinase (GLK; also termed MAP4K3) is a member of the MAP4K family, which is a subfamily of the sterile 20 protein-like serine/threonine kinases [7]. GLK contains a conserved N-terminal kinase domain, a conserved C-terminal citron homology domain and proline-rich motifs in the middle portion [7]. Lam et al. identified GLK as a novel inducer of apoptosis [9], and apoptosis plays an important role in the pathogenesis of autoimmune diseases $[10,11]$. Our recent study showed an increased GLK expression that positively correlated with disease severity in patients with SLE [12]. In addition, previous studies showed that GLK-deficient mice were resistant to experimental autoimmune encephalomyelitis (EAE) [12], mediated mainly by Th17 cells [13].

Adult-onset Still's disease (AOSD) is an inflammatory disorder characterized by fever, rash, arthritis, variable multisystemic involvement, and an increase of acute phase reactants $[14,15]$. Our previous studies and other reports have shown that the levels of proinflammatory cytokines including IL-1 $\beta$, IL-6, IL-18 and TNF- $\alpha$ are increased in patients with AOSD [16-19]. Furthermore, Th17 cells play an important role in the pathogenesis of AOSD [20]. These observations and a significant association of GLK with lupus disease activity [12] lead us to hypothesize that GLK may play a role in the pathogenesis of AOSD, which shares partial clinical manifestations with SLE. However, there is no data concerning GLK expression in AOSD.

In this study, we investigated whether GLK and Th17related cytokines were involved in the pathogenesis of AOSD. The associations of GLK expression with disease activity and clinical characteristics were examined in patients with AOSD. The changes in GLK expression during longitudinal follow-up of these patients were also studied.

\section{Methods \\ Participants}

Twenty-four consecutive patients visiting Taichung Veterans General Hospital, Taiwan, with active untreated AOSD (15 women and 9 men, mean age \pm SD, $33.3 \pm 9.9$ years) fulfilling the Yamaguchi criteria [21] were enrolled. Patients with infections, malignancies or other rheumatic diseases were excluded. The disease activity scores (range, 0 to 12 ) for each patient were assessed according to the criteria described by Pouchot et al. [22]. After an initial determination of the levels of circulating GLK-expressing T-cells and Th17-related cytokines, all patients with AOSD received corticosteroids and non-steroidal anti-inflammatory drugs. The disease-modifying anti-rheumatic drugs used were methotrexate (20 patients), hydroxychloroquine (18 patients), sulfasalazine (8 patients), and azathioprine (3 patients). Twelve age-matched healthy volunteers (eight women and four men, mean age $32.4 \pm 8.2$ years) who had no rheumatic disease served as normal controls. Peripheral blood was collected using endotoxin-free heparinized vacuum tubes (KABI-ET; Chromogenix, Antwerp, Belgium) to avoid cytokine production during the interval between sampling and culture. The Ethics Committee of Clinical Research, Taichung Veterans General Hospital, approved this study (No. C10130) and written consent was obtained from all participants according to the Declaration of Helsinki.

\section{Quantitation of circulating GLK-expressing T-cells using flow cytometry analysis}

Circulating GLK-expressing T-cells were quantified using flow cytometry analysis according to the technique described in a recent study [12]. Antibodies for GLK were generated by immunizing rabbits with individual peptides [12]. Briefly, peripheral blood mononuclear cells (PBMCs) were harvested, washed with cold PBS, and stained with the indicated antibodies for $30 \mathrm{~min}$ on ice. PBMCs were then treated with Golgi-stop $(10 \mu \mathrm{g} / \mathrm{mL}$ of Brefeldin A, Sigma, Schnelldorf, Deisenhofen, Germany) without any other stimulation and then stained with anti-CD3-allophycocyanin -Cy7,, anti-CD4-pacidic blue and anti-CD8-peridinin chlorophyll protein cyanin 5.5 (all BD Pharmingen, San Diego, CA, USA ), at room temperature (RT). For intracellular staining, PBMCs were permeabilized in $200 \mu \mathrm{L}$ Cytofix/Cytoperm buffer (BD Biosciences, San Diego, CA, USA) for $2 \mathrm{~h}$ and washed with Perm-Wash buffer. The pellet was incubated with $100 \mu \mathrm{L}$ Reagent 2, saponin (Beckman Coulter, Brea, CA, USA) for $5 \mathrm{~min}$ at in the dark. Samples were washed twice with $0.1 \%$ 
BSA-PBS, and incubated with phycoerythrin (PE)-conjugated GLK-specific mAb (eBiosciences, San Diego, CA, USA) for 30 minutes at in the dark. An isotype control IgG1-PE (eBiosciences) was used for GLK staining at RT in the dark. After staining, the cells were washed and immediately analyzed using flow cytometry (Beckman Coulter). Lymphocytes were gated on the basis of forward and size scatter properties, and at least $10,000 \mathrm{CD}^{+}$cells were analyzed. Data were collected using FACSCanto II flowcytometer (BD Biosciences) and analyzed by FlowJo software.

\section{Western blotting for GLK expression}

For immunoblotting analysis, samples of purified T-cell were performed as described in our recent study [12]. For GLK, an equal amount of cell extracts from each set of experiments were fractionated on $6 \%$ to $8 \%$ SDS-PAGE in running buffer (25 mM Tris, $192 \mathrm{mM}$ glycine, 0.1\% SDS). The gel was run at $90 \mathrm{~V}$ for $30 \mathrm{~min}$ then at $130 \mathrm{~V}$ until the blue dye front reached the bottom. The gel was transferred to polyvinylidene difluoride membrane in transfer buffer (50 mM Tris, $384 \mathrm{mM}$ glycine, $20 \%$ methanol) at $21 \mathrm{~V}$ for $1 \mathrm{~h}$ with the Trans-Blot SD Semi-Dry Electrophoretic Transfer Cell (Bio-Rad, Hercules, CA, USA). The membranes were blocked with 5\% BSA in Tris buffered saline with Tween (TBST) $(150 \mathrm{mM} \mathrm{NaCl}, 20 \mathrm{mM}$ Tris$\mathrm{HCl}(\mathrm{pH} 7.4), 0.1 \%$ Tween-20 ) at RT for $1 \mathrm{~h}$ then probed with Anti-GLK $(1: 1,000)$, which was generated by immunizing rabbits with the appropriate peptide and anti- $\beta$ tubulin (1:1,000 T4026, Sigma, St. Louis, Missouri, USA) at $4^{\circ} \mathrm{C}$ overnight. The membranes were washed about three times with TBST, followed by incubation with peroxidase-conjugated secondary antibody $(1: 6,000)$ at RT for $1 \mathrm{~h}$. The membranes of antibody reaction were washed three times with TBST and performed using the enhanced Immobilon Western Chemiluminescent HRP Substrate (WBKLS0500, Millipore, Billerica, Massachusetts, USA), exposed with a MegaCam 810 scientific grade CCD camera (UVP, LLC, Upland, CA, USA). The relative expression level of GLK protein was normalized to $\beta$-tubulin, and values were expressed relative to the control.

\section{Quantitative PCR for GLK expression}

PBMCs were immediately isolated from venous blood using Ficoll-Paque PLUS (GE Healthcare Biosciences, Uppsala, Sweden) density gradient centrifugation. Total cellular RNA was obtained from PBMCs by the guanidinium isothiocyanate method [23] and was quantified by spectrophotometry at $260 \mathrm{~nm}$. A $2.5 \mu \mathrm{g}$ RNA aliquot was reverse transcribed with $200 \mathrm{U}$ of Moloney murine leukemia virus reverse transcriptase (Fermentas, Thermo Fisher Scientific Inc.,Glen Burnie Maryland,USA) according to standard procedures. GLK mRNA expression levels were determined by quantitative PCR (qPCR) assay supplied in a TaqMan PCR Core Reagent Kit (Applied Biosystems, Foster City, CA, USA). Primers specific for GLK and the internal control glyceraldehydes-3-phosphate dehydrogenase (GAPDH) were obtained from Applied Biosystems. The purity of PCR products was assessed by dissociation curve plots. To standardize mRNA levels of GLK, transcript levels of the housekeeping gene GAPDH were also determined in parallel for each sample. The relative expression level of GLK was calculated with comparative threshold cycle $(\mathrm{Ct})$ method and evaluated by:

$2^{-\Delta \Delta \mathrm{Ct}}, \Delta \Delta \mathrm{Ct}=$ Patient $\left(\mathrm{Ct}_{\mathrm{GLK}}\right.$ gene $\left.-\mathrm{Ct}_{\mathrm{GAPDH}}\right)-$ Mean of controls $\left(\mathrm{Ct}_{\mathrm{GLK}}\right.$ gene $\left.-\mathrm{Ct}_{\mathrm{GAPDH}}\right)$.

\section{Determination of serum levels of soluble IL-2 receptor and Th17-related cytokines}

Serum soluble IL-2 receptor (sIL-2R) levels were determined using an ELISA kit (Cellfree; Endogen Inc., Woburn, MA, USA). Serum levels of IL-1 $\beta$, IL-6, IL-17A and TNF- $\alpha$ were determined in patients with AOSD and in healthy controls (HCs) using ELISA according to the manufacturer's instructions (eBiosciences).

\section{Statistical analysis}

Results are presented as the mean \pm SD or median (interquartile range). The nonparametric Kruskal-Wallis test was used for between-group comparison of the frequencies of circulating GLK-expressing T-cells, the expression levels of GLK transcript and protein, and serum levels of Th17-related cytokines. When this test showed significant differences, then the exact $P$-values were determined using the Mann-Whitney $U$ test. The correlation coefficient was calculated using the nonparametric Spearman's rank correlation test. Wilcoxon signed rank test was employed to compare the levels of circulating GLK-expressing T-cells and the expression levels of GLK during follow-up in patients with AOSD after effective therapy. A $P<0.05$ was considered significant.

\section{Results}

Clinical characteristics of patients with adult-onset Still's disease

As illustrated in Table 1, all 24 patients with active untreated AOSD had daily spiking fevers $\left(\geq 39^{\circ} \mathrm{C}\right)$. Other common manifestations included evanescent rash $(\mathrm{n}=$ $20,83.3 \%)$, sore throat $(\mathrm{n}=17,70.8 \%)$ and arthritis $(\mathrm{n}=$ $15,62.5 \%)$. Lymphadenopathy and hepatosplenomegaly were noted in $10(41.7 \%)$ and six (25.0\%) patients, respectively. There were no significant differences in age on entry to this study or the proportion of women between the patients with AOSD and HCs. 
Table 1 Demographic data and clinical characteristics of patients with adult-onset Still's disease and healthy controls

\begin{tabular}{lcc}
\hline Characteristics & Adult-onset Still's disease $(\mathbf{n}=\mathbf{2 4})$ & Healthy controls $(\mathbf{n}=\mathbf{1 2})$ \\
\hline Age at study entry (years) & $33.3 \pm 9.9$ & $32.4 \pm 8.2$ \\
Proportion of females & $15(62.5 \%)$ & $8(66.7 \%)$ \\
Fever $\left(\geq 38^{\circ} \mathrm{C}\right.$ ) & $24(100 \%)$ & $\mathrm{NA}$ \\
Evanescent rash & $20(83.3 \%)$ & $\mathrm{NA}$ \\
Sore throat & $17(70.8 \%)$ & $\mathrm{NA}$ \\
Arthritis & $15(62.5 \%)$ & $\mathrm{NA}$ \\
Lymphadenopathy $_{\text {Liver dysfunction }}^{\text {a }}$ & $10(41.7 \%)$ & $\mathrm{NA}$ \\
Hepatosplenomegaly & $10(41.7 \%)$ & $\mathrm{NA}$ \\
Clinical activity score & $6(25.0 \%)$ & $\mathrm{NA}$ \\
C-reactive protein $(\mathrm{mg} / \mathrm{dL})$ & $5.83 \pm 1.34$ & $\mathrm{NA}$ \\
Ferritin levels $(\mu \mathrm{g} / \mathrm{L})$ & $3.3 \pm 0.4$ & $\mathrm{NA}$ \\
Soluble $\mathrm{IL}-2 \mathrm{R}$ levels $(\mathrm{pg} / \mathrm{mL})$ & $692.9 \pm 103.6$ & $\mathrm{NA}$ \\
\hline
\end{tabular}

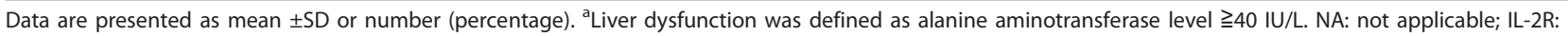
interleukin-2 receptor.

Increased frequencies of circulating GLK-expressing T-cells in patients with adult-onset Still's disease

Representative examples of flow cytometry contour plots of GLK expression in peripheral blood $\mathrm{CD}^{+} \mathrm{T}$-cells, $\mathrm{CD}^{+}{ }^{+} \mathrm{T}$-cells and $\mathrm{CD} 8^{+} \mathrm{T}$-cells of one patient with active AOSD and one $\mathrm{HC}$ are shown in Figure $1 \mathrm{~A}$ and $1 B$, respectively. Significantly higher median frequencies of circulating GLK-expressing $\mathrm{CD}^{+}$T-cells were observed in patients with active AOSD (median = $31.85 \%$, interquartile (IQ) range $21.21 \%$ to $48.84 \%$ ) than in $\mathrm{HCs}$ (median $=8.93 \%$, IQ range $6.81 \%$ to $12.08 \%$; $P<0.001$, Figure 1C).

\section{Increased expression of GLK transcripts and proteins in} patients with adult-onset Still's disease

As shown in Figure 1D, significantly greater fold increases in relative expression of GLK transcripts were observed in patients with active AOSD (median $=2.35$, IQ range 1.66 to 3.88 ) than in $\mathrm{HCs}$ (median $=0.92$, IQ range 0.63 to 1.37; $P<0.001$ ). Similarly, patients with active AOSD had increased expression of GLK in the lysates of purified $\mathrm{T}$-cells determined by western blotting (Figure 1E). The relative expression levels of GLK proteins in patients with active AOSD (median $=1.74$, IQ range 1.47 to 2.95 ) were significantly higher than those in controls (median $=0.66$, IQ range 0.54 to $0.94 ; P<0.001$, Figure $1 \mathrm{~F}$ ).

\section{Increased serum levels of Th17-related cytokines in patients with adult-onset Still's disease}

As shown in Figure 2, patients with active AOSD had significantly higher median levels of serum IL-6 (median = $474.81 \mathrm{pg} / \mathrm{mL}$, IQ range $156.42 \mathrm{pg} / \mathrm{mL}$ to $987.55 \mathrm{pg} / \mathrm{mL}$ ), IL-17A (median $=306.80 \mathrm{pg} / \mathrm{mL}$, IQ range $152.17 \mathrm{pg} / \mathrm{mL}$ to $503.70 \mathrm{pg} / \mathrm{mL}$ ) and TNF- $\alpha$ (median $=51.85 \mathrm{pg} / \mathrm{mL}$, IQ range $23.63 \mathrm{pg} / \mathrm{mL}$ to $65.93 \mathrm{pg} / \mathrm{mL}$ ) compared with those in $\mathrm{HCs}$ (median $=85.78 \mathrm{pg} / \mathrm{mL}$, IQ range $31.13 \mathrm{pg} / \mathrm{mL}$ to
$189.98 \mathrm{pg} / \mathrm{mL}, P<0.001$ for IL-6; median $=70.90 \mathrm{pg} / \mathrm{mL}$, IQ range $51.42 \mathrm{pg} / \mathrm{mL}$ to $124.53 \mathrm{pg} / \mathrm{mL}, P<0.001$ for IL-17A; and median $=24.66 \mathrm{pg} / \mathrm{mL}$, IQ range $10.50 \mathrm{pg} /$ $\mathrm{mL}$ to $37.76 \mathrm{pg} / \mathrm{mL}, P<0.01$ for TNF- $\alpha$ ). However, there was no significant difference in serum IL-1 $\beta$ levels between patients with AOSD and HCs.

\section{Correlation between GLK expression and disease activity} as well as cytokines in patients with adult-onset Still's disease

As illustrated in Table 2, the frequencies of circulating GLK-expressing $\mathrm{CD}^{+}{ }^{+} \mathrm{T}$-cells were positively correlated with disease activity, including clinical activity scores, $\mathrm{C}$-reactive protein levels, ferritin levels and serum levels of sIL-2R, which reflected T-cell activation in patients with AOSD. Similarly, the relative expression levels of GLK proteins and transcripts were positively correlated with clinical activity scores and sIL-2R levels in patients with AOSD. Among the Th17-related cytokines, GLK expression levels were positively correlated with serum levels of IL-6 and IL-17A. However, there was no significant correlation of GLK expression with clinical manifestations in our patients with AOSD (data not shown).

Changes in the levels of GLK expression in patients with adult-onset Still's disease after effective therapy

Twelve patients with AOSD were available for examination both at the active phase and at the remission phase. As shown in Figure 3, the percentages of circulating GLKexpressing T-cells and the relative expression levels (fold) of GLK proteins as well as transcripts were significantly decreased (mean \pm standard error of the mean, 45.77 $\pm 5.58 \%$ versus $20.11 \pm 2.53 \%$; $3.01 \pm 0.49$ versus $0.93 \pm 0.17$; and $3.45 \pm 0.56$ versus $1.21 \pm 0.38$, respectively, all $P<0.005)$, paralleling clinical remission and the decrease in serum levels of sIL-2R $(747.8 \pm 131.8 \mathrm{pg} / \mathrm{mL}$ versus 

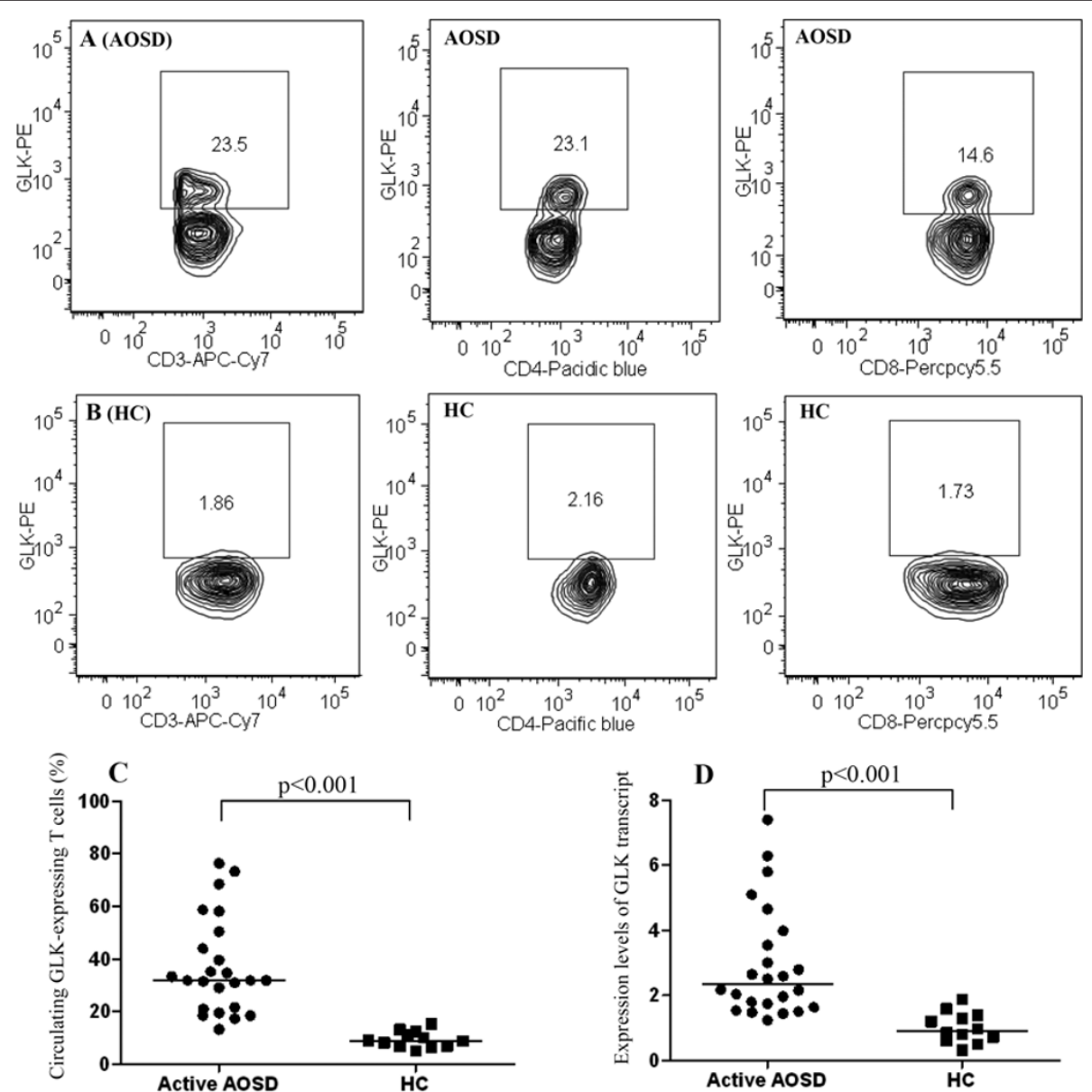

E
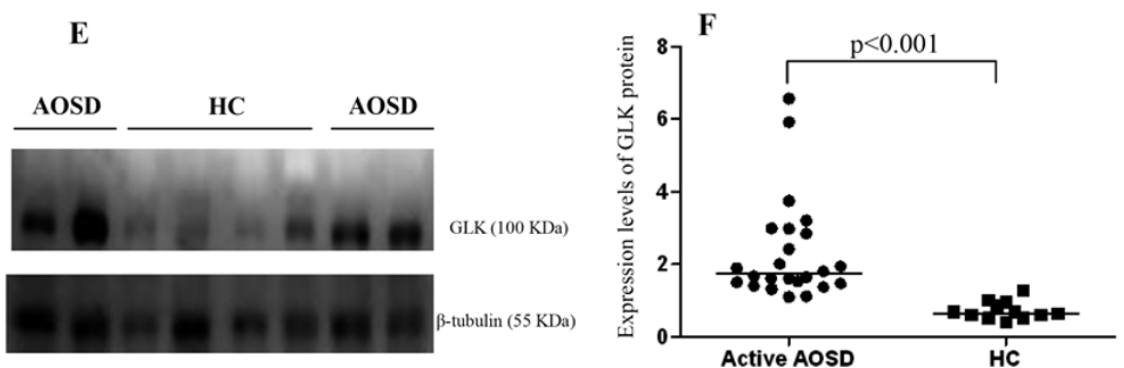

Figure 1 The GLK expression levels in T cells from patients with adult-onset Still's diseases and healthy controls. Representative examples of flow cytometry contour plots of intracellular GLK production in $\mathrm{CD}^{+}{ }^{+} \mathrm{T}$-cells, CD4 ${ }^{+} \mathrm{T}$-cells, and $\mathrm{CD} 8^{+} \mathrm{T}$-cells were obtained from peripheral blood of (A) one patient with AOSD and (B) one healthy control. (C) The frequencies of circulating GLK-expressing CD3 ${ }^{+}$T-cells were $^{-}$ obtained from 24 patients with active AOSD and $12 \mathrm{HC}$. (D) The comparison in the relative expression levels of GLK transcript between patients with AOSD and HC. (E) Immunoblot analyses of GLK expression in the lysates of peripheral blood T cells from patients with AOSD and HC. (F) The comparison in the relative expression levels of GLK protein between patients with active AOSD and HC. Horizontal bar indicates median value. *P-value was determined by Mann-Whitney U test. AOSD: adult-onset Still's disease; GLK: germinal center kinase-like kinase; HC: healthy control.

$229.1 \pm 38.5 \mathrm{pg} / \mathrm{mL}, P<0.005)$ in patients with AOSD after effective therapy.

\section{Discussion}

This study is the first investigation to demonstrate GLK overexpression in patients with active AOSD relative to
HCs. The advent of flow cytometry analysis of intracellular signaling molecules [24] has greatly expanded the opportunities to study a single cell in heterogeneous cell populations. In the present study, $\mathrm{CD}^{+} \mathrm{T}$-cells, including CD4 and CD8 subsets, demonstrated increased GLK expression in patients with active AOSD. Our results also 

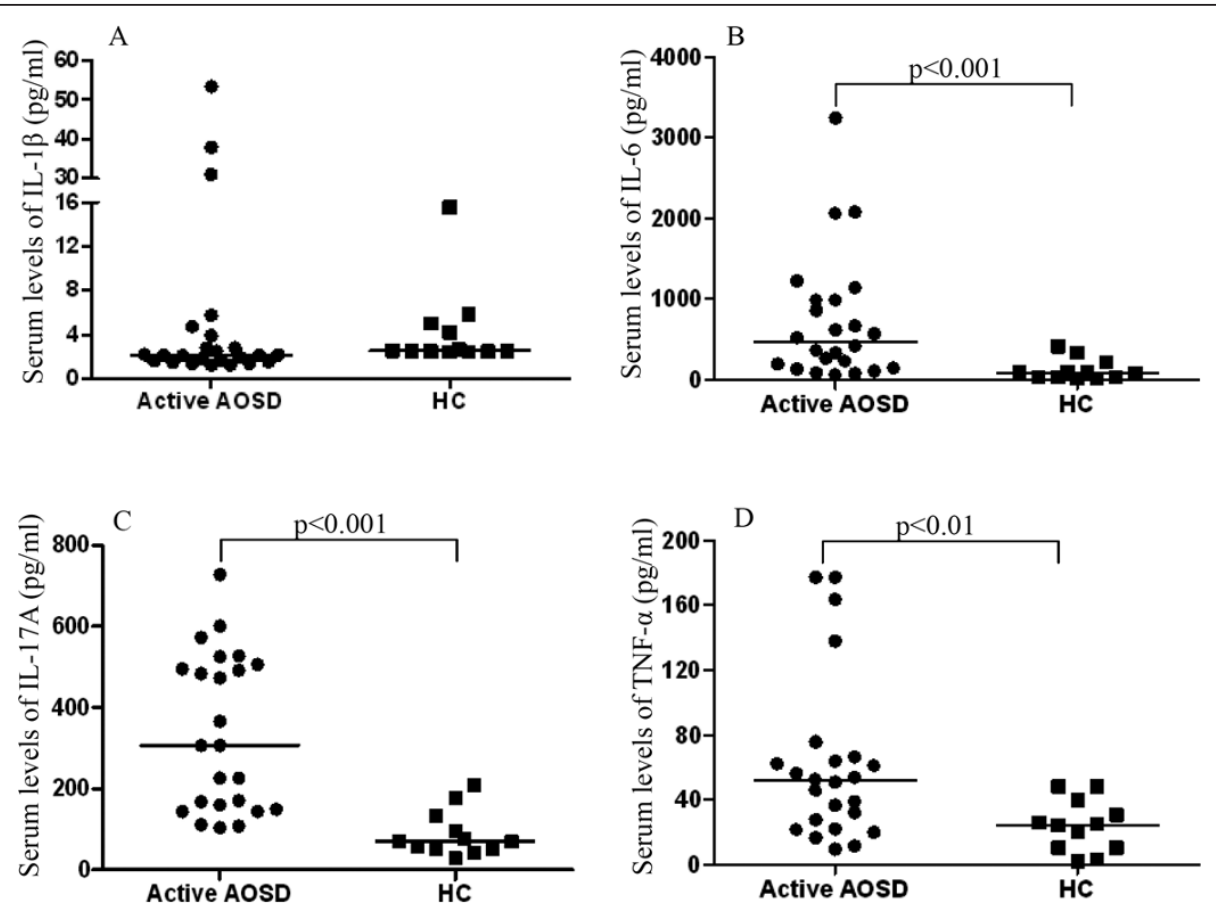

Figure 2 The comparison in serum levels of Th17-related cytokines from patients with active adult-onset Still's disease and healthy controls. (A) IL-1 $\beta$, (B) IL-6, (C) IL-17A, and (D) TNF- $\alpha$. Horizontal bar indicates median value. ${ }^{*} P$-value was determined by Mann-Whitney $U$ test. AOSD: adult-onset Still's disease; HC: healthy control.

showed significantly elevated frequencies of circulating GLK-expressing T-cells, which correlated with disease activity, including clinical activity scores and serum ferritin levels, in patients with AOSD. Moreover, a parallel decrease in GLK production with disease remission was found in these patients. These data concerning patients with AOSD were similar to the results of our recent study showing elevated levels of circulating GLK-expressing $\mathrm{T}$-cells correlating with activity index in patients with SLE [12], suggesting that GLK overexpression plays an important role in AOSD pathogenesis, and is thus a potential activity marker of this disease. However, a large prospective study should be conducted to confirm the findings presented here.

To verify GLK expression at the protein and transcript levels in patients with AOSD, western blotting and qPCR for GLK expression were performed in peripheral blood lymphocytes from our patients with active untreated AOSD. We have demonstrated that the relative expression levels of GLK proteins and transcripts were significantly

Table 2 The correlations between the frequencies of circulating GLK-expressing T-cells, the relative expression levels of GLK protein, GLK transcript and disease activity parameters as well as Th17-related cytokines in $\mathbf{2 4}$ patients with adult-onset Still's disease

\begin{tabular}{|c|c|c|c|}
\hline & $\begin{array}{l}\text { Circulating GLK- } \\
\text { expressing } \\
\text { T-cells (\%) }\end{array}$ & $\begin{array}{l}\text { Relative expression levels of GLK } \\
\text { protein }\end{array}$ & $\begin{array}{l}\text { Relative expression levels of GLK } \\
\text { transcript }\end{array}$ \\
\hline Clinical activity scores & $0.599^{* *}$ & $0.435^{*}$ & $0.452^{*}$ \\
\hline $\begin{array}{l}\text { C-reactive protein (mg/ } \\
\mathrm{dL} \text { ) }\end{array}$ & $0.455^{*}$ & 0.315 & 0.364 \\
\hline Ferritin $(\mu \mathrm{g} / \mathrm{L})$ & $0.508^{*}$ & 0.296 & 0.318 \\
\hline Soluble IL-2R ( $\mathrm{pg} / \mathrm{mL})$ & $0.865^{* * *}$ & $0.569^{* *}$ & $0.803^{* * *}$ \\
\hline $\mathrm{IL}-1 \beta(\mathrm{pg} / \mathrm{mL})$ & 0.281 & 0.152 & 0.063 \\
\hline IL-6 (pg/mL) & $0.822^{* * *}$ & $0.423^{*}$ & $0.547^{* *}$ \\
\hline IL-17A (pg/mL) & $0.787^{* * *}$ & $0.699^{* * *}$ & $0.740^{* * *}$ \\
\hline TNF- $\alpha(p g / m L)$ & 0.295 & 0.177 & 0.310 \\
\hline
\end{tabular}

GLK: germinal center kinase-like kinase; IL: interleukin; IL-2R: interleukin-2 receptor; TNF- $\alpha$ : tumor necrosis factor-alpha. ${ }^{*} P<0.05,{ }^{*} P<0.005,{ }^{* * *} P<0.001$ obtained by the nonparametric Spearman's rank correlation test. 

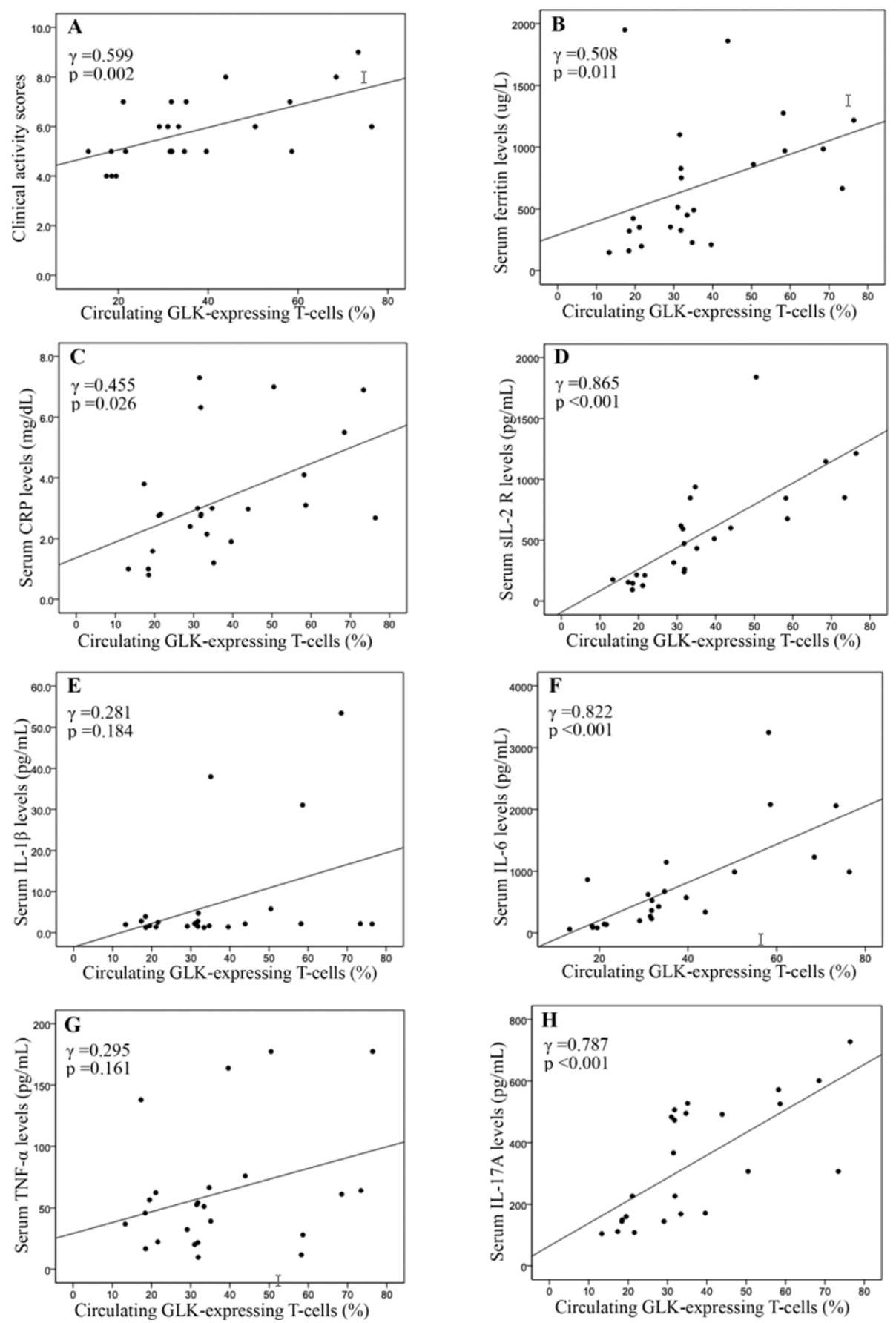

Figure 3 Correlation between GLK expression and disease activity parameters as well as cytokines in patients with adult-onset Still's disease. The correlation between the frequencies of circulating GLK-expressing T-cells and (A) disease activity score, activity parameters including (B) serum ferritin levels, (C) C-reactive protein levels and (D) soluble interleukin-2 receptor levels, and serum levels of cytokines including (E) IL-1 $\beta,(\mathbf{F}) I L-6,(\mathbf{G}) T N F-\alpha$ and $(\mathbf{H})$ IL-17A from 24 patients with adult-onset Still's disease. Correlation coefficients $(\gamma)$ and $P$-value were obtained by the nonparametric Spearman's rank correlation test. AOSD: adult-onset Still's disease; CRP: C-reactive protein; GLK: germinal center kinase-like kinase; IL: interleukin; sIL-2R: soluble interleukin-2 receptor levels; TNF- $\alpha$ : tumor necrosis factor-alpha.

higher in our patients than in HCs. Moreover, the positive correlations between the frequencies of circulating GLKexpressing T-cells and the expression levels of GLK proteins in our study are consistent with the findings of previous studies showing that intracellular flow cytometry and western blotting are equivalent assays for measuring MAPK signaling status [25,26]. In addition, the expression levels of GLK proteins as well as transcripts were 
significantly correlated with clinical activity scores in our patients with AOSD. These data provide the first direct and robust evidence of GLK overexpression in the T-cells of patients with AOSD.

Accumulating evidence indicates that Th17 cells play an important role in the pathogenesis of both AOSD and SLE $[20,27,28]$. IL- 6 synergizes with IL- $1 \beta$ to enhance the differentiation and generation of Th17 cells [29]. Th17 cells can secrete IL-17, a pleiotropic cytokine which participates in tissue inflammation by inducing the expression of proinflammatory cytokines and chemokines [30-32]. Our recent study showed that GLK-deficient mice are resistant to the development of EAE and showed decreased Th17 responses [12]. The results from in vitro $\mathrm{T}$-cell differentiation assays also indicate that GLK plays a positive role in Th17 cell differentiation [12]. In the present study, the results revealed elevated serum levels of Th17-related cytokines, IL-6 and IL-17A, which were correlated with the expression levels of GLK in T-cells from patients with AOSD. Our data also
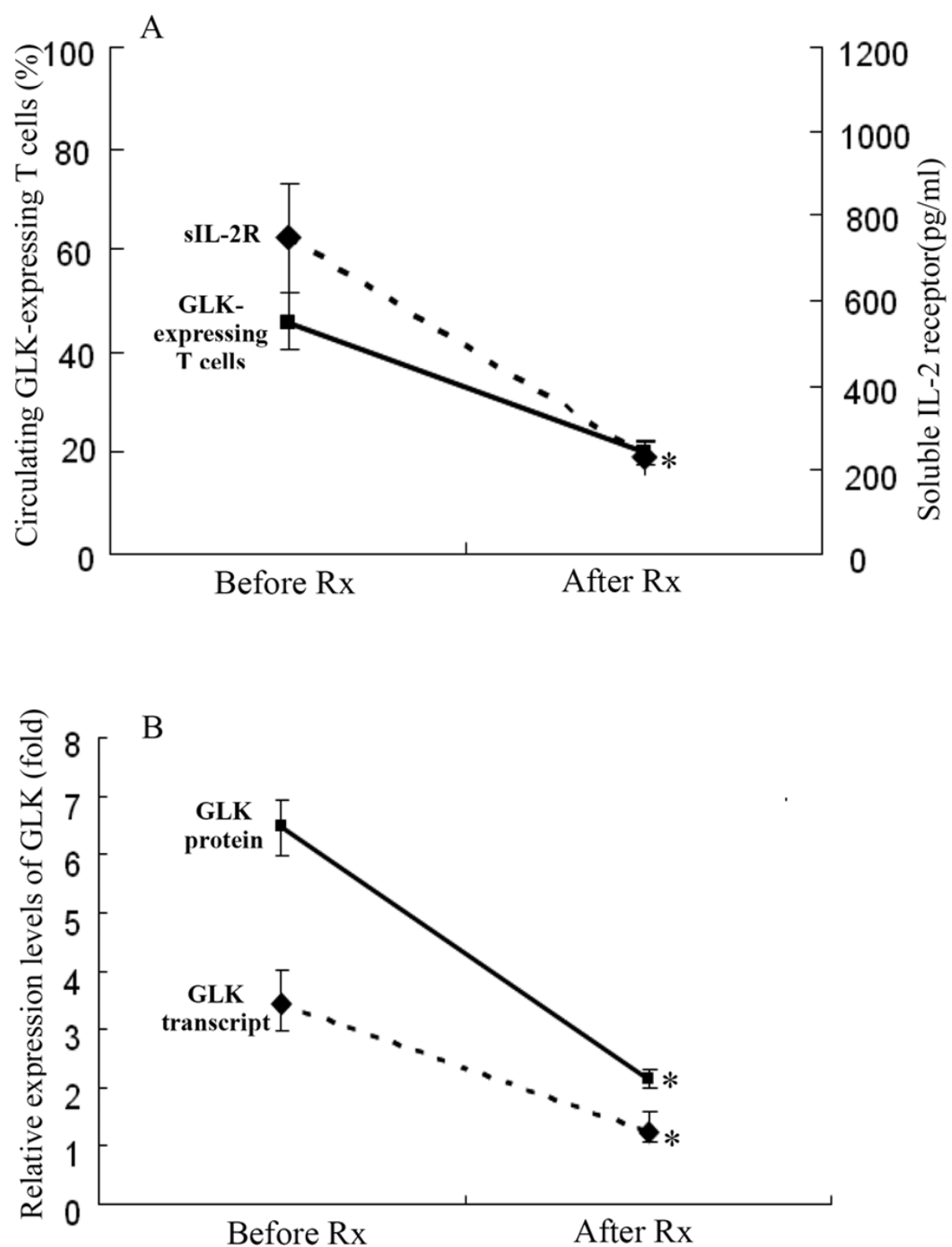

Figure 4 Changes in the levels of circulating GLK-expressing T-cells, the expression levels of GLK proteins as well as transcripts, and serum levels of soluble interleukin-2 receptor in 12 patients with adult-onset Still's disease after effective therapy. Data are presented as mean \pm standard error of the mean. ${ }^{*} P<0.005$ versus before treatment, determined by the Wilcoxon signed rank test. AOSD: adult-onset Still's disease; GLK: germinal center kinase-like kinase; sIL-2R: soluble interleukin-2 receptor. 
support previous findings showing that MAPK pathway plays an important role in the regulation of Th17 cell function [33], and that IL-17 production is mediated by a MAPK-dependent mechanism [34]. In addition, inhibition of MAPK could suppress IL-17 production in VogtKoyanagi-Harada syndrome [35], and attenuate the Th17-mediated autoimmune disease EAE [36]. These observations suggest either GLK overexpression or MAPK signaling can participate in the production of Th17-related cytokines. However, there still exists the possibility that GLK upregulation might represent an epiphenomenon of inflammation rather than a primary event in the pathogenesis of AOSD.

Our longitudinal follow-up of patients with AOSD showed a significant decrease in the levels of circulating GLK-expressing T-cells as well as the expression levels of GLK protein and transcript, paralleling the clinical remission and the decrease in inflammatory parameters after effective therapy (Figure 4). Our results support the hypothesis that inhibitors of more upstream MAPK signaling pathways, such as MAP2K (MKK3 or MKK6) and MAP3K (transforming growth factor activated kinase 1), can be a promising therapeutic modality for rheumatic diseases [37,38]. As an upstream MAPK, GLK could also be targeted as a potential therapeutic strategy by broadly inhibiting downstream MAPKs or several p38 isoforms $[39,40]$. Furthermore, upstream signaling molecules might be better targets than downstream molecules such as p38MAPK, blockade of which could result in considerable toxic effects $[37,41,42]$.

There were some limitations in this study. Because biopsy tissue is difficult to obtain, we did not investigate the GLK expression in lesion specimens from patients with AOSD. Although some studies reported elevated IL- $1 \beta$ levels in AOSD and a substantial benefit of IL- $1 \beta$ receptor antagonist (anakinra) for treatment of inflammatory diseases $[43,44]$, our results showed no significant difference in IL-1 $\beta$ levels between patients with AOSD and healthy volunteers. This discrepancy may result from differences in the detection methods or other unknown confounding factors undetected in this study. The lack of any significant association of GLK expression with clinical features may be owing to the small sample size in this clinically heterogeneous and uncommon disease.

\section{Conclusions}

Our results revealed that GLK overexpression with increasing levels of Th17-related cytokines may be involved in the pathogenic mechanisms of AOSD. Our data add to the evidence supporting the association between GLK overexpression and a list of inflammatory diseases. We also showed that GLK expression levels were positively correlated with disease activity of AOSD, indicating that GLK might be a novel activity biomarker and a potential therapeutic target. Further investigations are required to confirm and extend this current finding.

\section{Abbreviations}

AOSD: adult-onset Still's disease; BSA: bovine serum albumin; EAE: experimental autoimmune encephalomyelitis; GAPDH: glyceraldehydes-3phosphate dehydrogenase; GLK: germinal center kinase-like kinase; HC: healthy control; IL: interleukin; IQ: interquartile; JNK: c-Jun N-terminal kinase; MAPKs: mitogen-activated protein kinases; NF: nuclear factor; PBMCs: peripheral blood mononuclear cells; PBS: phosphate-buffered saline; qPCR: quantitative polymerase chain reaction; SD: standard deviation; SIL-2R: soluble interleukin-2 receptor; SLE: systemic lupus erythematosus; TBST: Tris buffered saline with Tween; Th: T helper; TNF-a: tumor necrosis factor-alpha.

\section{Acknowledgements}

This work was supported by a grant from Taichung Veterans General Hospital (TCVGH-1003803C and TCVGH-100NHRI01) and by a grant from the National Science Council, Taiwan (NSC-98-2314-B-075A-003-MY3).

\section{Author details}

'Division of Allergy, Immunology and Rheumatology, Taichung Veterans General Hospital and Faculty of Medicine, National Yang Ming University, Taiwan. ${ }^{2}$ School of Medicine, Chung Shan Medical University, Taichung, Taiwan. ${ }^{3}$ Institute of Biomedical Science, National Chung Hsing University, Taichung, Taiwan. ${ }^{4}$ Immunology Research Center, National Health Research Institutes, Zhunan, Taiwan. ${ }^{5}$ Department of Pathology \& Immunology, Baylor College of Medicine, Houston, Texas, USA.

\section{Authors' contributions}

All authors made substantive intellectual contributions to the present study and approved the final manuscript. D-YC conceived of the study, generated the original hypothesis, designed the study, acquired clinical data, performed data analysis, and drafted and revised the manuscript. T-HT conceived of the study, generated the original hypothesis, designed the study, performed statistical analysis, and revised the manuscript. H-CC, J-LL and Y-MC contributed equally on this work, and performed data acquisition and statistical analysis. W-TH and K-LL carried out clinical assessments on study participants.

\section{Competing interests}

The authors declare that they have no competing interests.

Received: 16 March 2012 Accepted: 6 August 2012

Published: 6 August 2012

\section{References}

1. Chang L, Karin M: Mammalian MAP kinase signaling cascades. Nature 2001, 410:37-40.

2. Raman M, Chen W, Cobb MH: Differential regulation and properties of MAPKs. Oncogene 2007, 26:3100-3112.

3. Sweeney SE, Firestein GS: Primer: signal transduction in rheumatic disease - a clinician's guide. Nat Clin Pract Rheumatol 2007, 3:651-660.

4. Wong CK, Li PW, Lam CW: Intracellular JNK, p38 MAPK and NF-kappaB regulate IL-25 induced release of cytokines and chemokines from costimulated T helper lymphocytes. Immunol Lett 2007, 112:82-91.

5. Wong CK, Wong PTY, Tam LS, Li EK, Chen DP, Lam CWK: Activation profile of intracellular mitogen-activated protein kinases in peripheral lymphocytes of patients with systemic lupus erythematosus. J Clin Immunol 2009, 29:738-746.

6. Noubade $R$, Krementsov DN, del Rio R, Thornton T, Nagaleekar $V$, Saligrama N, Spitzack A, Spach K, Sabio G, Davis RJ, Rincon M, Teuscher C: Activation of P38 MAPK in CD4 T cells controls IL-17 production and autoimmune encephalomyelitis. Blood 2011, 118:3290-3300.

7. Diener K, Wang XS, Chen C, Meyer CF, Keesler G, Zukowski M, Tan TH, Yao Z: Activation of the c-Jun N-terminal kinase pathway by a novel protein kinase related to human germinal center kinase. Proc Natl Acad SCi USA 1997, 94:9687-9692. 
8. Findlay GM, Yan L, Procter J, Mieulet V, Lamb RF: A MAP4 kinase related to Ste20 is a nutrient-sensitive regulator of mTOR signaling. Biochem J 2007, 403:13-20.

9. Lam D, Dickens D, Reid EB, Loh SH, Moisoi N, Martins LM: MAP4K3 modulates cell death via the post-transcriptional regulation of $\mathrm{BH} 3$-only proteins. Proc Natl Acad Sci USA 2009, 106:11978-11983.

10. Lorenz HM, Grunke M, Hieronymus T, Herrmann M, Kuhnel A, Manger B, Kalden JR: In vitro apoptosis and expression of apoptosis-related molecules in lymphocytes from patients with systemic lupus erythematosus and other autoimmune disease. Arthritis Rheum 1997, 40:306-317.

11. Chen DY, Hsieh TY, Hsieh CW, Lin FJ, Lan JL: Increased apoptosis of peripheral blood lymphocytes and its association with interleukin-18 in patients with active untreated adult-onset Still's disease. Arthritis Rheum 2007, 57:1530-1538.

12. Chuang HC, Lan JL, Chen DY, Yang CY, Chen YM, Li JP, Huang CY, Liu PE, Wang X, Tan TH: GLK controls autoimmunity and NF-kB signaling by activating PKC $\theta$ in T cells. Nature Immunol 2011, 12:1113-1118.

13. Lock C, Hermans G, Pedotti R, Brendolan A, Schadt E, Garren H, LangerGould A, Strober S, Cannella B, Allard J, Klonowski P, Austin A, Lad N, Kaminski N, Galli SJ, Oksenberg JR, Raine CS, Heller R, Steinman L: Genemicroarray analysis of multiple sclerosis lesions yields new targets validated in autoimmune encephalomyelitis. Nat Med 2002, 8:500-508.

14. Bywaters EGL: Still's disease in the adults. Ann Rheum Dis 1971, 30:121-133.

15. Ohta A, Yamaguchi M, Kaneoka H, Nagayoshi T, Hiida M: Adult Still's disease: review of 228 cases from the literature. J Rheumatol 1987, 14:1139-1146.

16. Kawashima M, Yamamura M, Taniai M, Yamauchi $H$, Tanimoto $T$, Kurimoto M, Miyawaki S, Amano T, Takeuchi T, Makino H: Levels of interleukin-18 and its binding inhibitors in the blood circulation of patients with adult-onset Still's disease. Arthritis Rheum 2001, 44:550-560

17. Chen DY, Lan JL, Lin FJ, Hsieh TY: Proinflammatory cytokine profiles in the sera and in the pathological tissues of patients with active untreated adult onset Still's disease. J Rheumatol 2004, 31:2189-2198.

18. Choi JH, Suh CH, Lee YM, Suh YJ, Lee SK, Kim SS, Nahm DH, Park HS: Serum cytokine profiles in patients with adult onset Still's disease. J Rheumatol 2003, 30:2422-2427.

19. Chen DY, Lan JL, Lin FJ, Hsieh TY, Wen MC: A predominance of Th1 cytokine in peripheral blood and pathological tissues of patients with active untreated adult-onset Still's disease. Ann Rheum Dis 2004 63:1300-1306

20. Chen DY, Chen YM, Lan JL, Lin CC, Chen HH, Hsieh CW: Potential role of Th17 cells in the pathogenesis of adult-onset still's disease. Rheumatology (Oxford) 2010, 49:2305-2312.

21. Yamaguchi M, Ohta A, Tsunematsu $T$, Kasukawa R, Mizushima $Y$ Kashiwagi S, Tanimoto K, Matsumoto Y, Ota T: Preliminary criteria for classification of adult Still's disease. J Rheumatol 1992, 19:424-430.

22. Pouchot J, Sampalis JS, Beaudet F, Carette S, Décary F, SalusinskySternbach M, Hill RO, Gutkowski A, Harth M, Myhal D: Adult Still's disease: manifestations, disease course, and outcome in 62 patients. Medicine 1991, 70:118-136.

23. Chomczynski P, Sacchi N: Single-step method of RNA isolation by acid guanidium thiocyanate-phenol-chloroform extraction. Anal Biochem 1987, 162:156-159.

24. Krutzik PO, Irish JM, Nolan JP, Perez OD: Analysis of protein phosphorylation and cellular signaling events by flow cytometry: techniques and clinical applications. Clin Immunol 2004, 110:206-221.

25. Grammer AC, Swantek JL, MCFarland RD, Miura Y, Geppert T, Lipsky PE: TNF receptor-associated factor- 2 signaling mediates activation of p38 and Jun $\mathrm{N}$-terminal kinase, cytokine secretion, and lg production following ligation of CD40 on human B cells. J Immunol 1998, 161:1183-1193.

26. Grammer AC, Fischer R, Lee O, Zhang X, Lipsky PE: Flow cytometric assessment of the signaling status of human $B$ lymphocytes from normal and autoimmune individuals. Arthritis Res Ther 2004, 6:28-39.

27. Yang J, Chu Y, Yang X, Gao D, Zhu L, Yang X, Wan L, Li M: Th17 and natural Treg cell population dynamics in systemic lupus erythematosus. Arthritis Rheum 2009, 60:1472-1483.

28. Garrett-Sinha LA, John S, Gaffen SL: IL-17 and the Th17 lineage in systemic lupus erythematosus. Curr Opin Rheumatol 2008, 20:519-525.

29. Zhou L, Ivanov II, Spolski R, Min R, Shenderov K, Egawa T, Levy DE, Leonard WJ, Littman DR: IL-6 programs $T(H)-17$ cell differentiation by promoting sequential engagement of the IL-21 and IL-23 pathways. Nat Immunol 2007, 8:967-974.

30. Park H, Li Z, Yang XO, Chang SH, Nurieva R, Wang YH, Wang Y, Hood L, Zhu Z, Tian Q, Dong C: A distinct lineage of CD4 T cells regulates tissue inflammation by producing interleukin 17. Nat Immunol 2005, 6:1133-1141

31. Jovanovic DV, Di Battista JA, Martel-Pelletier J, Jolicoeur FC, He Y, Zhang M, Mineau F, Pelletier JP : IL-17 stimulates the production of proinflammatory cytokines, IL-1 $\beta$ and TNF- $\alpha$, by human macrophages. J Immunol 1998, 160:3513-3521.

32. Laan M, Cui AH, Hoshino H, Lötvall J, Sjöstrand M, Gruenert DC, Skoogh BE, Lindén A: Neutrophil recruitment by human IL-17 via CXC chemokine release in the airways. J Immunol 1999, 162:2347-2352.

33. Fedele G, Spensieri F, Palazzo R, Nasso M, Cheung GY, Coote JG, Ausiello CM: Bordetella pertussis commits human dendritic cells to promote a Th1/Th17 response through the activity of adenylate cyclase toxin and MAPK-pathways. PLOS One 2010, 5:e8734.

34. Roussel L, Houle F, Chan C, Yao Y, Bérubé J, Olivenstein R, Martin JG, Huot J, Hamid Q, Ferri L, Rousseau S: IL-17 promotes p38 MAPKdependent endothelial activation enhancing neutrophil recruitment to sites of inflammation. J Immunol 2010, 184:4531-4537.

35. Commodaro AG, Bombardieri CR, Peron JPS, Saito KC, Guedes PM, Hamassaki DE, Belfort RN, Rizzo LV, Belfort R Jr, de Camargo MM: p38a MAP kinase controls IL-17 synthesis in Vogt-Koyanagi-Harada syndrome and experimental autoimmune uveitis. Invest Ophthalmol Vis Sci 2010, 51:3567-3574.

36. Brereton CF, Sutton CE, Lalor SJ, Lavelle EC, Mills KHG: Inhibition of ERK MAPK suppresses IL-23 and IL-1-driven IL-17 production and attenuates autoimmune disease. J Immunol 2009, 183:1715-1723.

37. Hammaker D, Firestein GS: 'Go upstream, young man': lessons learnt from the p38 saga. Ann Rheum Dis 2010, 69(Suppl.1):77-82.

38. Hammaker DR, Boyle DL, Inoue T, Firestein GS: Regulation of the JNK pathway by TGF-beta activated kinase 1 in rheumatoid arthritis synoviocytes. Arthritis Res Ther 2007, 9:R57.

39. Yoshizawa T, Hammaker D, Boyle DL, Corr M, Flavell R, Davis R, Schett G, Firestein GS: Role of MAPK kinase 6 in arthritis: distinct mechanism of action in inflammation and cytokine expression. J Immunol 2009, 183:1360-1367.

40. Gaestel M, Mengel A, Bothe U, Asadullah K: Protein kinases as small molecule inhibitor targets in inflammation. Curr Med Chem 2007, $14: 2214-2234$.

41. Kremer JM, Bloom BJ, Breedveld FC, Coombs JH, Fletcher MP, Gruben D, Krishnaswami S, Burgos-Vargas R, Wilkinson B, Zerbini CA, Zwillich SH: The safety and efficacy of a JAK inhibitor in patients with active rheumatoid arthritis: results of a double-blind, placebo-controlled phase lla trial of three dosage levels of CP-690,550 versus placebo. Arthritis Rheum 2009, 60:1895-1905

42. Genovese MC, Kavanaugh A, Weinblatt ME, Peterfy C, DiCarlo J, White ML, O'Brien M, Grossbard EB, Magilavy DB: An oral Syk kinase inhibitor in the treatment of rheumatoid arthritis: a three-month randomized, placebocontrolled, phase II study in patients with active rheumatoid arthritis that did not respond to biologic agents. Arthritis Rheum 2011, 63:337-345.

43. Kötter I, Wacker A, Koch S, Henes J, Richter C, Engel A, Günaydin I, Kanz L: Anakinra in patients with treatment-resistant adult-onset Still's disease: four case reports with serial cytokine measurements and a review of the literature. Semin Arthritis Rheum 2007, 37:189-197.

44. Braddock M, Quinn A: Targeting IL-1 in inflammatory disease: new opportunities for therapeutic intervention. Nat Rev Drug Discov 2004, 3:330-339.

\section{Pre-publication history}

The pre-publication history for this paper can be accessed here: http://www.biomedcentral.com/1741-7015/10/84/prepub

doi:10.1186/1741-7015-10-84

Cite this article as: Chen et al:: Germinal center kinase-like kinase (GLK/ MAP4K3) expression is increased in adult-onset Still's disease and may act as an activity marker. BMC Medicine 2012 10:84. 